\title{
Knowledge and Behavior of Dentists, and Practice Modifications in Response to the Outbreak of Novel COVID-19 in Dentists of Pakistan
}

\author{
Nosheen Sarwar ${ }^{1} \quad$ BDS \\ Saba Ansar ${ }^{2} \quad$ BDS \\ Momminah Qamar ${ }^{3} \quad$ BDS
}

OBJECTIVES: The current study is conducted to assess the knowledge and behavior of dentists in Pakistan and various practice modifications adopted in response to current outbreak of COVID-19.

METHODOLOGY: Well-constructed online questionnaires were distributed among 300 subjects including dental students (3rd year and 4th year), house surgeons, and dental surgeons of two public hospitals of Punjab, Pakistan.

RESULTS: $90 \%$ of dentists are afraid of getting the infection and reluctant to continue their dental practice. Most of the dentists 95\% are aware of the mode of transmission of disease and follow WHO guidelines but still a large number of dentists are in fear and anxious to perform only emergency dental procedures.

CONCLUSION: Most dentists resume their dental practice by following WHO new guidelines related to practice in COVID -19 outbreak but still a significant number of dentists close their dental practice for an indefinite period due to anxiety and fear of being ill or got infected by COVID-19.

KEYWORD: anxiety and fear, practice modifications, outbreak, COVID-19, knowledge and behavior

HOW TO CITE: Sarwar N, Ansar S, Qamar M. Knowledge and behavior of dentists, and practice modifications in response to the outbreak of novel COVID-19 in dentists of Pakistan. J Pak Dent Assoc 2021;30(4):261-266.

DOI: https://doi.org/10.25301/JPDA.304.261

Received: 27 November 2020, Accepted: 07 August 2021

\section{INTRODUCTION}

$\mathrm{T}$ he outbreak of COVID-19 started from Wuhan, a city in China now spread globally and adversely affects every aspect of life. ${ }^{1}$ The disease-causing organism identified as a single strand RNA virus, a new strain of severe acute respiratory syndrome-Coronavirus2 (Sars-CoV-2) named coronavirus 19 or COVID-19. ${ }^{2}$ After the initial case was reported the WHO declared the COVID-19 pandemic, a worldwide public health-related emergency. ${ }^{3}$

Data from published epidemiological and virologic studies provide evidence that COVID-19 is primarily transmitted from symptomatic persons to others who are in close contact through respiratory droplets, by direct contact with infected persons, or by contact with contaminated objects and surfaces. ${ }^{4}$ The average incubation period of the virus is 2 weeks range from 3-14 days. ${ }^{5}$

The clinical manifestations show by the patients are mainly upper respiratory tract symptoms and fever. ${ }^{6}$ But

1. House Officer, Department of Dentistry, Punjab Dental Hospital, Lahore, Pakistan.

2. House Officer, Department of Dentistry, Allied Hospital Faisalabad, Pakistan.

3. House Officer, Department of Dentistry, Punjab Dental Hospital, Lahore, Pakistan.

Corresponding author: "Dr. Nosheen Sarwar" <nosheensarwar48@gmail.com > now studies supported those respiratory symptoms are not initial symptoms presented in COVID-19 patients but the earliest symptoms seen are headache, fever ageusia, anosmia, and in some cases, diarrhea was also reported. ${ }^{7}$

In this pandemic situation, health care workers perform a main front line role so they are more prone to the virus as compared to the normal population. ${ }^{8}$ Similarly, the dentist treated the patient in close vicinity and dental instruments produce aerosols and splashes of saliva in the oral cavity which can affect the dentists and dental assistants. ${ }^{9}$ So in this situation when everyone is in the fear of getting infection people are reluctant to go to their workplaces. ${ }^{10}$ On the other hand, dentists which are at high risk are expected to develop fear and anxiety of getting an infection, being isolated and being infected to their family. ${ }^{11}$ Considering the rapid spread of disease the American Dental Association (ADA) highlights the additional precautions along with slandered universal precautions including the travel history, temperature checking, pre-rinse with antiseptic mouth wash, and cleaning and disinfecting the areas which are in contact with patients and public. ${ }^{12}$ These guidelines help to reduce fear and anxiety in dentists but still mostly dentists are unaware of ADA guidelines they are reluctant to perform 
procedures. ${ }^{13,14}$ The current study is conducted to evaluate the factors which are causing fear and anxiety in dentists and accessing the practice modifications to combat the COVID 19.

\section{METHODOLOGY}

A cross-sectional study was carried out, by an online organized questionnaire, among the dental students and dental professionals of Punjab Dental Hospital Lahore, Pakistan (de' Montmorency College of Dentistry) and the Dental section of Allied Hospital (Faisalabad Medical University) Faisalabad, Pakistan. The study participants included are Dental surgeons, House Surgeons, 3rd year and 4th-year dental students that were practicing during the pandemic. The students of non-clinical years, dental technicians and paramedics were excluded from the study. The time duration to conduct this study was about one week from 21-06-2020 to 28-06-2020. The approval for this study was taken from the ethical committee of respective institute (FMU/08/2020/03).

The response form appendix no. 1 was prepared in Google forms and send through WhatsApp and Email. The informed consent was also taken online. The response form was sent to 300 subjects out of which 270 were filled and used in the study. The sample size was calculated by Open Epi online software by taking 50\% knowledge awareness with a $5.05 \%$ margin of error and $92 \%$ confidence interval. The size obtained was 265 and it is considered 300 to compensate for any flaws and data errors.

The questionnaire was based on three sections. The first section was about demographic data of participating candidates; the second section contains questions exploring fear and anxiety of dental students and professionals related to COVID-19, the questions of the third section are about knowledge and practice modifications of dental students and professionals to prevent the cross-infection of COVID19 among dentist and patient. The total number of questions in the questionnaire were 28 . The time taken to fill this questionnaire was approximately 2-3 minutes.

\section{STATISTICAL ANALYSIS}

The questionnaire/Proforma was made on Google form and results from data was compiled using SPSS version 21.0 (SPSS Inc., Chicago, IL, USA). The descriptive variables like age, gender and designation of study participants were described in the form of frequency and percentages. A Chi-Square test was used to assess the relation of gender and knowledge of COVID-19. $p<0.05$ was considered significant in statistic.

\section{RESULTS}

A total of 300 questioners were distributed among dental students, house surgeons, and dental surgeons of two public teaching hospitals of Punjab. By considering the current lockdown and pandemic situation all the questionnaires were filled by online Google forms. The time duration of the response form filing was 3 days. A total of 270 forms were collected back so the response rate of the study was $90 \%$. The questionnaire was divided into 3 sections. The first section is about the demographic details of participants which are elaborated in Table 1 . Out of 270 participants, $202(74.8 \%)$ were female and $68(25.2 \%)$ were

Table 1: Demographic details of participants $(n=270)$

\begin{tabular}{lcc}
\hline \hline Profiles & Frequency (n) & Percentage (\%) \\
\hline Gender & 68 & $25.2 \%$ \\
Male & 202 & $74.8 \%$ \\
Female & & \\
& & \\
Age group(years) & 4 & $6 \%$ \\
$<20$ & 236 & $83.1 \%$ \\
$20-30$ & 30 & $10.9 \%$ \\
$\geq 30$ & & \\
Designation & & $17.8 \%$ \\
Dental students & 48 & $24.1 \%$ \\
House surgeons & 65 & $58.1 \%$ \\
Dental surgeons & 157 & \\
\hline \hline
\end{tabular}

males so the ratio of female participants was more like other epidemiological studies. About the designation of participants, there were 48 (17.8\%) dental students of 3rd and 4 th year who practice their clinical rotations in a hospital setting. $65(24.1 \%)$ were house surgeons and the remaining were dental surgeons 157 (58.1\%). Related to the age distribution of participants $83.1 \%$ of participants were between $20-30$ years. 0nly $6 \%$ were below 20 and the remaining $10.9 \%$ above 30 years. The p-value of 0.07 , which is negligible, indicates that there is no direct relationship between gender and COVID-19 practice modifications.

In section 2 of the response form, dentists' behaviors in coronavirus outbreaks were assessed and the factors which cause fear and anxiety were also tried to rule out. The 217 (80.4\%) dentists were afraid of being ill with COVID $-19.91 \%$ of participants were reluctant to come to their workplace in the current pandemic. $76.3 \%$ of dental persons feel anxious when taking the patient in close vicinity. Due to this anxious behavior, most of the dentists (71.9\%) feel reluctant to perform an oral examination of their 
patients. The reason for this fear can be that they are afraid to carry infection to their home which can infect their family or friends $(88.1 \%)$. The other factor of being afraid is that dentists are anxious about the cost of treatment $(67.4 \%)$ and the other reason can be that there is only symptomatic treatment is present and there is no vaccine available for the treatment of COVID -19 (table 2).

Table 2: Assessment behavior of dentists in outbreak

\begin{tabular}{|c|c|c|c|}
\hline Variables & Yes n $(\%)$ & Non $(\%)$ & "Maybe n(\%) \\
\hline $\begin{array}{l}\text { Are You Afraid of Getting Infected } \\
\text { with COVID-19 from a Patient and } \\
\text { Co-Worker? }\end{array}$ & $217(80.4 \%)$ & $27(10 \%)$ & $26(9.6 \%)$ \\
\hline $\begin{array}{l}\text { Are You Afraid of the coming } \\
\text { hospital in the current pandemic } \\
\text { situation? }\end{array}$ & $206(76.3 \%)$ & $46(17 \%)$ & $18(6.7 \%)$ \\
\hline $\begin{array}{l}\text { Do You Feel anxious when Talking } \\
\text { to Patients in Close Vicinity? }\end{array}$ & $221(81.9 \%)$ & $27(10 \%)$ & $22(8.1 \%)$ \\
\hline $\begin{array}{l}\text { do you feel reluctant in an oral } \\
\text { examination of the patient? }\end{array}$ & $194(71.9 \%)$ & $43(15.9 \%)$ & $33(12.2 \%)$ \\
\hline $\begin{array}{l}\text { Do You Have Fear that You Could } \\
\text { Carry the Infection from Your } \\
\text { Dental Practice back to Your } \\
\text { Family? }\end{array}$ & $238(88.1 \%)$ & $15(5.6 \%)$ & $17(6.3 \%)$ \\
\hline $\begin{array}{l}\text { Are You Anxious about the Cost of } \\
\text { Treatment if You Get Infected? }\end{array}$ & $182(67.4 \%)$ & $61(22.6 \%)$ & $27(10 \%)$ \\
\hline $\begin{array}{l}\text { Do You feel Afraid when you Hear } \\
\text { that People are Dying Because of } \\
\text { COVID-19? }\end{array}$ & $216(80 \%)$ & $29(10.7 \%)$ & $25(9.3 \%)$ \\
\hline
\end{tabular}

The third section is about the practice modifications and knowledge about the coronavirus in dentists and dental students. 249 (92.2\%) dentists were aware of the mode of transmission of COVID -19. But only $88.1 \%$ of dentists know the current WHO guidelines about COVID -19.

Related to practice modifications in response to outbreaks it is a common practice in dentists to ask about the travel history and history of fever and recent illness to the patients $(85.2 \%)$. It is also common to check the temperature of the patient before entering a hospital which is a good practice in this outbreak. Most of the dentists (84.1\%) defer the dental treatment of the patient who shows any suspicious symptom. Only 105 (38.9\%) dentists considered that a surgical mask is enough for protection from the virus. While $93 \%$ of dental persons are agreed that N-95 masks should wear in routine dental practice. On the other hand, a very small number $(23.3 \%)$ of dentists ever wear the N-95 mask in their dental practice.

Almost all of the dentists (87.8\%) followed the universal precaution of infection control in their dental practice. But ask the Patient to Rinse His/her Mouth with Anti-Bacterial Mouthwash before treatment is not a common practice in dentists $72(26.7 \%) .69 .6 \%$ of dentists use personal protective
Table 3: Knowledge and practice modification in response to COVID-19

\begin{tabular}{|c|c|c|c|}
\hline Variables & Yes n(\%) & Non(\%) & May be $n(\%)$ \\
\hline $\begin{array}{l}\text { Are You Aware of the Mode of Transmission of } \\
\text { COVID-19? }\end{array}$ & $249(92.2 \%)$ & $13(4.8 \%)$ & $8(3 \%)$ \\
\hline $\begin{array}{l}\text { Are You Updated with the Current CDC or WHO } \\
\text { Guidelines for Cross-Infection Control regarding } \\
\text { COVID-19? }\end{array}$ & $238(88.1 \%)$ & $17(6.3 \%)$ & $15(5.6 \%)$ \\
\hline $\begin{array}{l}\text { Are You currently Asking every Patient's Travel } \\
\text { History before Performing Dental Treatment? Are } \\
\text { You Currently Taking every Patient's Body } \\
\text { Temperature before Performing Dental Treatment? }\end{array}$ & $230(85.2 \%)$ & $27(10 \%)$ & $13(4.8 \%)$ \\
\hline $\begin{array}{l}\text { Are You Deferring Dental Treatment of Patients } \\
\text { Showing Suspicious Symptoms? }\end{array}$ & $227(84.1 \%)$ & $30(11.1 \%)$ & $13(4.8 \%)$ \\
\hline $\begin{array}{l}\text { Do You Think Surgical Mask is enough to Prevent } \\
\text { cross-infection of COVID 19? }\end{array}$ & $105(38.9 \%)$ & $152(56.3 \%)$ & $13(4.8 \%)$ \\
\hline $\begin{array}{l}\text { Do You Think N-95 Mask should be Routinely } \\
\text { Worn in Dental Practice due to the Current } \\
\text { Outbreak? }\end{array}$ & $251(93 \%)$ & $11(4.1 \%)$ & $8(3 \%)$ \\
\hline $\begin{array}{l}\text { Have You Ever Worn an N-90 Mask while Treating } \\
\text { a Patient in Your Dental Practice? }\end{array}$ & $63(23.3 \%)$ & $200(74.1 \%)$ & $7(2.6 \%)$ \\
\hline $\begin{array}{l}\text { Do You Routinely Follow Universal Precautions of } \\
\text { Infection Control for Every Patient? }\end{array}$ & $237(87.8 \%)$ & $15(5.6 \%)$ & $18(6.7 \%)$ \\
\hline $\begin{array}{l}\text { Do You Ask Every Patient to Rinse His/her Mouth } \\
\text { with Anti-Bacterial Mouthwash before Treatment? }\end{array}$ & $72(26.7 \%)$ & $184(68.1 \%)$ & 14(5.25) \\
\hline $\begin{array}{l}\text { Do You Wash Hands with Soap and Water/Use } \\
\text { Sanitizer Before and After Treatment of Every } \\
\text { Patient? }\end{array}$ & $246(91.1 \%)$ & $17(6.3 \%)$ & $7(2.6 \%)$ \\
\hline $\begin{array}{l}\text { Are You Aware of which Authority to Contact if } \\
\text { You Come Across a Patient with Suspected } \\
\text { COVID-19 Infection? }\end{array}$ & $45(16.7 \%)$ & $216(80 \%)$ & $9(3.3 \%)$ \\
\hline Do you use a PPE kit to examine every patient? & $188(69.6 \%)$ & $75(27.8 \%)$ & $7(2.6 \%)$ \\
\hline $\begin{array}{l}\text { Do you only perform the emergency procedure in } \\
\text { the current pandemic? }\end{array}$ & $225(83.3 \%)$ & $33(12.2 \%)$ & $12(4.4 \%)$ \\
\hline
\end{tabular}

equipment (PPE) to examine the patients and only $16.7 \%$ of dentists know the procedure to Contact the Authority if they Come Across a Patient with Suspected COVID-19 Infection. In this outbreak situation, most of the dentists $(83.3 \%)$ only perform emergency dental procures due to anxiety and fear related to COVID-19.

\section{DISCUSSION}

The study was conducted online by preparing and then filling out a questionnaire from dental students and dental professionals in two large public dental teaching hospitals of Punjab, Pakistan to access the dentists' awareness and behavior, as well as the effect of the COVID-19 outbreak on dental practice in Pakistan

A close-ended questionnaire was prepared and after filling assessed by statistical software to carry out complete results. The candidates included in this study have submitted their consent online through Google Form. The number of female participants $202(74.8 \%)$ is higher than male participants $68(25.2 \%)$ that result contradict the study result of Italy. ${ }^{15}$ By the designation, the number of dental students of the third year and final year who participate in clinical work was is $48(17.8 \%)$. The house surgeons were $65(24.1 \%)$ and the remaining $(58.1 \%)$ are dental surgeons.

In this pandemic situation of COVID-19 anxiety among 
every person especially in medical professionals are common. By analysis of the data obtained from the study, the result is that $76.3 \%$ of dental professionals feel anxious when taking the patient in close vicinity that have similar result with the study of Dolar Doshi in India. ${ }^{10}$ Due to this anxious behavior, most of the dentists $(71.9 \%)$ feel reluctant to perform an oral examination of their patients. The reason for this behavior is that there is no medicine and proper treatment of COVID-19 is still available and it is difficult to control due to its fast-spreading ration all around the world. It is affecting every person irrespective of gender and age. As the infected person doesn't show symptoms before two weeks but they remain the source to infect the other persons come in contact with them during this symptomless incubation period. So, diagnosing an infected person during this incubation period is difficult. And lack of diagnostic test kits due to limited resources, every person testing for COVID-19 is not possible. Another reason which makes the diagnosis difficult is that its cost is not affordable for every person as the economic condition of most of the population is already not good due to lockdown in the country. This damage to the economy of the country and its population also worsens the situation and increases the anxiety among the population.

The fear to get infected by COVID - 19 from patients is also present in this alarming situation of COVID-19 in 217 (80.4\%) dental practitioners the results supported by the study in South Sulawesi, Indonesia where $86 \%$ of dentists have fear of getting infected. ${ }^{17}$ As the main source of transfer of infection is droplets and aerosols coming from airway passage during breathing through nose and mouth and it is the part of the body to which the dentist has to deal. So, the dentist would be at greater risk to get infected during the treatment of a person infected with COVID-19.

Dental practitioners are also worried about spreading the infection to their families. ${ }^{8}$ That is the reason, dentists avoid continuing their practice in this situation they close their clinics and quit private practice temporarily during this alarming condition of COVID-19, which affects their economies. In this situation of COVID-19 to continue their profession and to protect themselves and their family members, the proper knowledge about COVID-19 must have dental professionals. This knowledge should include COVID-19 mode of transmission, its sign, and symptoms, measurements are taken to prevent the cross-infection between dental, professionals, and patients, what to do if they get infected or susceptive to have an infection, whom to contact in this situation. All of this knowledge is very necessary for dental professionals to cope up with this pandemic of COVID-19. In this study, we have to try to explore the knowledge of dental professionals about COVID-19.

The presence of this knowledge is not enough but the implication of this knowledge in his routine and professional practice is also necessary. By keeping in mind this knowledge dental professionals have needed to modify their practice for the best advantage of themselves, their families, and patients. In this study, these practice modifications by dental professionals have also been explored. ${ }^{18}$ These practice modifications are a sign of the implication of knowledge which is necessary to cope up with this situation of COVID-19. There is no evidence or confirmation that when vaccine or proper treatment for COVID-19 will be invented. So, we have to live and survive in this condition. For survival, time demands to continue their practice with modifications $(85.2 \%)$. Dental professionals are taking complete history including travel history, any sign and symptoms related to COVID-19 like sour throat, cough (if present either productive or non-productive), fever, or recent illness, and these results are also supported by the study of COVID-19. ${ }^{1}$ All these parameters of the history are important, the presence or absence of these points gives a clue to the dentist either is the patient is a suspect for COVID-19 or not. If the presence any positive clue the patient can be advised to test for COVID-19. Thus, early diagnosis and early treatment will be advantageous for the patient and indirectly for society. ${ }^{19}$ This application of history questionnaire will reduce the number of people infected by asymptomatic COVID-19 positive individuals.

The results of the current study are supported by the other studies of Covid in dentists of Pakistan. ${ }^{20}$ Study on the phycological fear of COVID-19, a high level of anxiety and fear reported in Pakistani dentists. ${ }^{21}$ In other study, $75 \%$ of dentists are afraid of getting Infected, and about more than 80 percent are anxious while treating the patients. ${ }^{22}$ Dentists in Pakistan are now well aware of the mode of transmission of COVID-19 still, a large population of the population don't utilize the basis isolation equipment's. ${ }^{23}$

The 69.6\% use the PPA kit in their dental set up to examine the patients. It is a positive sign that dentists adopted the essential safety measure to reduce the speed of disease these are according to ADA guidelines. ${ }^{14}$ About (93\%) dentists wear the N-95 masks in their routine practice that supported with the study results of clinical practice adjustments. ${ }^{18}$ The percentage of dental professionals taking other modifications like doing only emergency procedures like managing trauma and deferring from elective and routine dental procedures, wearing a surgical mask, agreeing on wearing N-95 mask, contact the authority if come across a susceptive COVID-19 positive patient, although not hundred percent still is appreciable. Which is a good sign 
towards the good surviving and managing ability during this pandemic COVID-19 situation.

\section{CONCLUSION}

The purpose of the current research is to rule out or evaluate the knowledge and behavior of dental students and dental professionals and practice modifications they followed in the COVID-19 outbreak. Most of the dentists are afraid of becoming ill since there is no medicine available and the cost and resources to fight against COVID-19 are not enough. WHO Infection Management Guidelines or ADA guidelines are 14 effective in relieving this anxiety and uncertainty, but it will still take some time to overcome the current situation until new ways are discovered to cope with the novel virus.

\section{CONFLICT OF INTEREST}

None to declare

\section{REFERENCES}

1. Ahmed MA, Jouhar R, Ahmed N, Adnan S, Aftab M, Zafar MS, et al. Fear and practice modifications among dentists to combat novel coronavirus disease (COVID-19) outbreak. Int J Environ Res Public Health. 2020;17: 2821.

https://doi.org/10.3390/ijerph17082700

2. Consolo U, Bellini P, Bencivenni D, Iani C, Checchi V. Epidemiological aspects and psychological reactions to COVID-19 of dental practitioners in the Northern Italy districts of modena and reggio emilia. Int J Environ Res Public Health. 2020; 17: 3459. https://doi.org/10.3390/ijerph17103459

3. Guan W, Ni Z, Hu Y, Liang W, Ou C, He J, et al. Clinical characteristics of coronavirus disease 2019 in China. N Engl J Med. 2020; 382:1708-1720.

http://.doi.org/10.1056/NEJMoa2002032

4. Khurshid Z, Asiri FYI, Al Wadaani H. Human saliva: Non-invasive fluid for detecting novel coronavirus (2019-nCoV). Int J Environ Res Public Health. 2020; 17:17-20.

http://.doi.org/10.3390/ijerph17072225

5. Backer JA, Klinkenberg D, Wallinga J. Incubation period of 2019 novel coronavirus $(2019 \mathrm{nCoV})$ infections among travellers from Wuhan, China, 2028 January 2020. Eurosurveillance. 2020; 25:16.

https://doi.org/10.2807/1560-7917.ES.2020.25.5.2000062

6. Chen N, Zhou M, Dong X, Qu J, Gong F, Han Y, et al. Epidemiological and clinical characteristics of 99 cases of 2019 novel coronavirus pneumonia in Wuhan, China: a descriptive study. Lancet.2020; 395(10223):507-13. http://.doi.org/10.1016/S0140-6736(20)30211-7
7. Corman VM, Landt O, Kaiser M, Molenkamp R, Meijer A, Chu DKW, et al. Detection of 2019 novel coronavirus (2019-nCoV) by real-time RT-PCR. Eurosurveillance. 2020; 25:1-8.

https://doi.org/10.2807/1560-7917.ES.2020.25.3.2000045

8. Kumar J, Katto MS, Sahito B, Ahmed B, Siddique AA, Jamil M, et al. Predictive Factors Associated with Fear Faced by Healthcare Workers during Covid-19 Pandemic: A Questionnaire Based Study. (Preprint) [Internet]. JMIR Publications Inc.; 2020. Available from: http://doi.org/10.2196/preprints.20881

9. Bizzoca ME, Campisi G, Muzio L Lo. Covid-19 Pandemic: What Changes for Dentists and Oral Medicine Experts? A Narrative Review and Novel Approaches to Infection Containment. Int J Environ Res Public Health. 2020; 17(11)379.

https://doi.org/10.3390/ijerph17113793

10.Doshi D, Karunakar P, Sukhabogi JR, Prasanna JS, Mahajan SV. Assessing Coronavirus Fear in Indian Population Using the Fear of COVID-19 Scale. Int J Ment Health Addiction [Internet]. 2020 May 28; Available from:

http://doi.org/10.1007/s11469-020-00332

11. Cagetti MG, Cairoli JL, Senna A, Campus G. COVID-19 outbreak in North Italy: An overview on dentistry. A questionnaire survey. Int J Environ Res Public Health. 2020; 17(11).

https://doi.org/10.3390/ijerph17113835

12. Ather A, Patel B, Ruparel NB, Diogenes A, Hargreaves KM. Coronavirus Disease 19 (COVID-19): Implications for Clinical Dental Care. J Endod. 2020; 46:584-95.

https://doi.org/10.1016/j.joen.2020.03.008

13. Barabari P, Moharamzadeh K. Novel Coronavirus (COVID-19) and Dentistry-A Comprehensive Review of Literature. Dent J. 2020; 8:53.

https://doi.org/10.3390/dj8020053

14. American Dental Association. Summary of ADA guidance during the COVID-19 crisis. Ada [Internet]. 2020;19-20. Available from: https://www.ada.org/en/press-room/news-releases $/ 2020$ archives/april/summary-of-ada guidance-during-the-covid-19-crisis.

15. Amato A, Ciacci C, Martina S, Caggiano M, Amato $M$. COVID-19: The Dentists' PerceivedImpact on the Dental Practice. Eur J Dent [Internet]. 2021 Feb 23; Available from: https://doi.org/10.1055/s-0040-1721910

16. Weiss SR, Navas-Martin S. Coronavirus Pathogenesis and the Emerging Pathogen Severe

Acute Respiratory Syndrome Coronavirus. Microbiol Mol Biol Rev. 2005; 69:635-64.

https://doi.org/10.1128/MMBR.69.4.635-664.2005

17. Pasiga BD. Relationship knowledge transmission of covid-19 and fear of dental care during pandemic in South Sulawesi, Indonesia. Pesqui Bras Odontopediatria Clin Integr. 2020; 21:1-12.

https://doi.org/10.1590/pboci.2021.017 
18. Schultz L, Link MP, Rheingold S, Hawkins DS, Dome JS, Wickiser J, et al. Summary of COVID-19 clinical practice adjustments across select institutions. Pediatr Blood Cancer.2020;67:1-2. https://doi.org/10.1002/pbc.28411

19. Xu G, Yang Y, Du Y, Peng F, Hu P, Wang R, et al. Clinical Pathway for Early Diagnosis of COVID-19: Updates from Experience to Evidence-Based Practice. Clin Rev Allergy Immunol. 2020; 59:89100 .

https://doi.org/10.1007/s12016-020-08792-8

20. Almas K, Khan AS, Tabassum A, Nazir MA, Afaq A, Majeed A. Knowledge, Attitudes, and Clinical Practices of Dental Professionals during COVID-19 Pandemic in Pakistan. Eur J Dent. 2020; 14 (S 01): S63-S69.

https://doi.org/10.1055/s-0040-1718785
21.Majeed MM, Saleem Z, Sarwar H, Ramzan Z, Iqbal SN, Naeem MM. The Psychology of Coronavirus Fear: Are Dentists of Pakistan Suffering from Corona-Phobia?. J Pak Dent Assoc. 2021; 30:1-6. https://doi.org/10.25301/JPDA.301.1

22. Kamran R, Saba K, Azam S. Impact of COVID-19 on Pakistani dentists: a nationwide cross-sectional study. BMC Oral Health. 2021; 21(1).

https://doi.org/10.1186/s12903-021-01413-6

23. Rauf S. Anxiety, Fear and Awareness of Pakistani Dentists Against Novel Coronavirus Disease (COVID-19): A Cross-Sectional Study. J Dent Oral Sci. 2021; 3:1-8.

https://doi.org/10.37191/Mapsci-2582-3736-3(1)-076 